\title{
HUBUNGAN PENGETAHUAN KELUARGA TENTANG DIIT DIABETES MELLITUS DENGAN KADAR GULA DARAH PASIEN
}

\section{FAMILY KNOWLEDGE RELATION TO DIIT DIABETES MELLITUS WITH BLOOD SUGAR LEVELS OF PATIENTS}

\author{
${ }^{1}$ Yusnita, ${ }^{2}$ Arena Lestari \\ ${ }^{1,2}$ Fakultas Kesehatan Universitas Muhammadiyah Pringsewu Lampung \\ e-mail; umiyusnita@gmail.com)
}

\begin{abstract}
ABSTRAK
Diabetes mellitus merupakan salah satu penyakit tidak menular. Di Indonesia pada tahun 2020 diperkiraan penderita diabetes mellitus (DM) meningkat menjadi 300 juta orang dan tahun 2030 menjadi 366 juta orang.Penatalaksanaan DM adalah: diit, latihan fisik/olahraga, pemantauan gula darah, minum obat, dan edukasi. Pengetahuan pasien dan keluarga tentang penyakit ini membantu dalam proses penyembuhan. Pengetahuan keluarga tentang DM merupakan sarana yang dapat membantu penderita DM dalam menjalankan diit selama hidupnya. Dengan diit DM yang baik maka kadar gula darah akan terkontrol dan pasien menjadi sehat. Tujaun penelitan adalah untuk mengetahui hubungan pengetahuan keluarga tentang diit DM dengan kadar gula darah pasien di wilayah kerja puskesmas Pringsewu tahun 2019. Penelitian ini menggunakan metode survey analitik . rancangan penelitian yang digunakan adalah cross sectional. Sampel yang digunakan berjumlah 75 orang. Hasil Analisa data dengan uji chi square menunjukkan nilai $p$ value 0.000 , maka dapat disimpulkan bahwa ada pengaruh yang signifikan anatar pengetahuan keluarga tentang diit DM dengan kadar gula darah pasien. Penderita dan keluarga pasien DM perlu mendapatkan informasi tentang pengetahuan dasar DM, pemantauan mandiri, penyebab peningkatan kadar gula darah, obat hipoglikemia, diit DM, pemeliharaan kaki, kegiatan jasmani dan komplikasi. Pengetahuan ini disampaikan secara bertahap. Tujuan pendidikan kesehatan bagi pasien DM adalah meningkatkan pengetahuan karena pengetahuan merupakan titik tolak perubahan sikap dan gaya hidup, sehingga terjadi perubahan perilaku pasien DM dan meningkatnya kepatuhan yang selanjutnya meningkatkan kualitas hidup. Kesimpulan dari penelitian ini adalah: ada hubungan antara pengetahuan keluarga tentang diit diabetes mellitus dengan kadar gula darah pasien diwilayah kerja puskesmas Pringsewu tahun 2019.
\end{abstract}

Kata kunci: Pengetahuan DM keluarga, gula darah.

\begin{abstract}
Diabetes Mellitus is one of the uncontagious diseases. In Indonesia in 2020 estimated diabetics (DM) sufferers increased to 300 million people and the year 2030 to 366 million people. The management of DM is: diit, physical/sports exercise, monitoring blood sugar, taking medication, and education. Patient and family knowledge of the disease helps in the healing process. Family knowledge about DM is a tool that can help DM people in running elemental during his life. With a good elemental DM then blood sugar levels will be controlled and the patient becomes healthy. The study is to know the relation of family knowledge about elemental DM with blood sugar level of patients in Pringsewu puskesmas work area in 2019. This research uses analytical survey methods. The research draft used is cross sectional. Samples used amounted to 75 people. Data analysis results with Chi Square test shows the value of P value 0.000 , it can be concluded that there is a significant influence about the family knowledge of elemental DM with blood sugar level of the patient. Patient and family DM patients need to get information on basic knowledge of DM, selfmonitoring, causes increase in blood sugar levels, hypoglycemia drugs, DM Elemental, foot maintenance, physical activities and complications. This knowledge is delivered gradually. The goal of health education for DM patients is to increase knowledge because knowledge is the starting point of changing attitudes and lifestyle, so that there is a change in the behaviour of DM patients and increasing adherence that further improves the quality of life. The conclusion of the study is: there is a relationship between family knowledge about elemental diabetes mellitus with blood sugar levels of the patient in Pringsewu puskesmas work area in 2019
\end{abstract}

Keywords: Knowledge of family DM, blood sugar 


\section{PENDAHULUAN}

Diabetes Mellitus (DM) merupakan kelompok penyakit gangguan metabolisme kronis yang ditandai dengan peningkatan kadar glukosa darah (hiperglikemia), dan disebabkan karena ketidakseimbangan antara suplai dan kebutuhan insulin. Insulin dalam tubuh dibutuhkan untuk memfasilitasi masuknya glukosa dalam sel agar dapat digunakan untuk metabolisme dan pertubuhan sel. Berkurang atau tidak adanya insulin menjadikan glukosa tertahan di dalam darah dan menimbulkan peningkatan gula darah, sementara sel menjadi kekurangan glukosa yang sangat dibutuhkan dalam kelangsungan dan fungsi sel ${ }^{1}$. Data dari studi global International Diaebetes Federation (IDF) menunjukan bahwa jumlah penderita diabetes mellitus pada tahun 2012 mencapai lebih dari 371 juta orang. Data prevalensi diabetes mellitus pada tahun 2013 mencapai 391,8 juta, dimana angka ini memberikan indikasi yang mengkhawatirkan masa depan. Diabetes dianggap sebagai ancaman utama untuk pembangunan global ${ }^{2}$. Di Indonesia pada tahun 2020 diperkiraan penderita diabetes mellitus (DM) meningkat menjadi 300 juta orang dan tahun 2030 menjadi 366 juta orang ${ }^{3}$. Berdasarkan data ${ }^{4}$ kejadian diabetes mellitus di provinsi Lampung mengalami peningkatan sebesar 1,1 \% (2007) menjadi 2,1 \% (2015). Sedangkan data dari Dinas Kesehatan Kabupaten Pringsewu, pada tahun 2016 data kunjungan penderita diabetes mellitus diliwayah kabupaten Pringsewu sebesar 670 orang penderita diabetes mellitus dan pada tahun 2014 sebesar 1195 penderita diabetes mellitus ${ }^{5}$. Penatalaksanaan DM yaitu dengan diit, latihan fisik/olahraga , pemantauan gula darah, minum obat, dan edukasi. Pengetahuan keluarga tentang DM merupakan penunjang yang dapat membantu pasien selama hidupnya. Keluarga yang memahami tentang penyakit DM semakin mengerti bagaimana dalam menyediakan diit DM sesuai aturan untuk keluarga yang menderita $\mathrm{DM}^{6}$. Pola makan yang baik memberikan peluang keberhasilan empat kali dalam pengelolaan DM. Menurut pendapat ${ }^{7}$ dari Medical Centre Institute, dalam penatalaksanaan diit DM ada tiga " J" yang harus diketahui dan dilaksanakan oleh penderita DM yaitu Jumlah makanan, jenis makanan dan jadwal makanan. Kontrol diit DM yang baik dapat menstabilkan kadar gula darah dalam tubuh, sementara control diit DM yang tidak baik menyebabkan percepatan munculnya komplikasi sistemik pada penderita DM seperti: kebutaan, penyakit jantung dan juga penyakit ginjal.

\section{METODE}

Penelitian ini menggunakan metode survey analitik. Rancangan penelitian yang digunakan adalah cross sectional. Populasi pada penelitian ini yaitu semua keluarga penderita diabetes mellitus tipe 2 yang ada di wilayah puskesmas kabupaten pringsewu periode tahun 2019. Sedangkan populasi studi/sampel adalah subyeksubyek dari populasi sumber yang benar-benar akan diteliti yaitu semua keluarga penderita DM tipe II di wilayah kerja puskesmas Pringsewu pada periode Agustus- Oktober 2018 sebanyak 75 orang. Teknik pengambilan sampel dengan Total sampling atau seluruh populasi diambil sebagai sampel berjumlah 75 orang. Instrument untuk 
variabel pengetahuan keluarga tentang diit DM digunakan kuesioer. Kuesioner dibagikan pada responden guna mengetahui pengetahuan responden tentang jumlah makanan, jenis makanan dan jadwal makanan penderita DM, berjumlah 20 pertanyaan. Instrument untuk variabel kadar gula darah digunakan lembar observasi kadar gula darah. Analisis bivariat variabel dependen dan independent menggunakan uji chi square, karena variabel pengetahuan keluarga dan kadar gula darah pasien diabetes mellitus dikelompokkan menjadi katagorik.

\section{HASIL}

Tabel 1

Distribusi Frekuensi Responden Berdasarkan Pengetahuan Keluarga tentang Diit DM

\begin{tabular}{ccc}
\hline Pengetahuan & Frekuensi & Presentase (\%) \\
\hline Kurang baik & 46 & 61,3 \\
Baik & 29 & 38,7 \\
Jumlah & $\mathbf{7 5}$ & $\mathbf{1 0 0}$
\end{tabular}

Dari tabel 1 diketahui bahwa sebagian besar keluarga responden dengan DM tipe II memiliki pengetahuan yang kurang baik yaitu sebanyak 46 responden $(61,3 \%)$.

Tabel 2

Distribusi Frekuensi Responden Berdasarkan Kadar Gula Darah Pasien

\begin{tabular}{ccc}
\hline Pengetahuan & Frekuensi & Presentase (\%) \\
\hline Kurang baik & 45 & 60 \\
Baik & 30 & 40 \\
Jumlah & $\mathbf{7 5}$ & $\mathbf{1 0 0}$
\end{tabular}

Tabel 2 menunjukkan 45 responden (60\%) memiliki kadar gula darah yang tidak normal.
Tabel 3

Hubungan Pengetahuan Keluarga Tentang Diit Diabetes Mellitus Dengan Kadar Gula Darah Pasien

\begin{tabular}{|c|c|c|c|c|c|c|c|c|}
\hline \multirow{3}{*}{$\begin{array}{c}\text { Pengetahuan } \\
\text { Keluarga }\end{array}$} & \multicolumn{4}{|c|}{ Kadar Gula Darah } & \multirow{2}{*}{\multicolumn{2}{|c|}{ Total }} & \multirow{3}{*}{$\begin{array}{c}P \\
\text { Value }\end{array}$} & \multirow{3}{*}{$\begin{array}{r}\text { OR } \\
95 \%\end{array}$} \\
\hline & \multicolumn{2}{|c|}{$\begin{array}{c}\text { Tidak } \\
\text { normal }\end{array}$} & \multicolumn{2}{|c|}{ Normal } & & & & \\
\hline & $\mathrm{n}$ & $\%$ & $\mathrm{n}$ & $\%$ & $\mathrm{~N}$ & $\%$ & & \\
\hline Kurang & 41 & 89,1 & 5 & 10,9 & 46 & 100 & 0,000 & 15,242 \\
\hline Baik & 4 & 13,8 & 25 & 86,2 & 29 & 100 & & $\begin{array}{l}12,566- \\
20,018\end{array}$ \\
\hline Total & 45 & 51,2 & 30 & 48,8 & 75 & 100 & & \\
\hline
\end{tabular}

Hasil penelitian pada tabel 3 menunjukkan bahwa presentase pengetahuan keluarga kurang baik pada responden yang memiliki kadar gula darah tidak normal adalah $89,1 \%$ lebih besar dari keluarga responden yang memiliki pengetahuan baik dan mempunyai kadar gula darah tidak normal yaitu sebesar $13,8 \%$, hal ini menunjukkan perbedaan yang signifikan. Hasil uji statisrik chi-square diperoleh $p$ value 0.000 , maka dapat disimpulkan bahwa ada pengaruh yang signifikan antara pengetahuan keluarga tentang diet DM dengan kadar gula darah pasien DM tipe II. Hasil peneliian ini juga mendapatkan nilai OR > 1 yaitu sebesar 15 hal ini menunjukkan bahwa bahwa variabel pengetahuan keluarga tentang diet diabetes mellitus merupakan faktor resiko terjadinya ketidaknormalan kadar gula darah pada pasien DM tipe II. Hasil nilai OR menunjukkan bahwa seseorang yang memiliki pengetahuan keluarga kurang baik beresiko 15 kali memiliki kadar gula darah tidak normal. 


\section{Wacana Kesehatan Vol. 4 , No.2, Desember 2019}

\section{PEMBAHASAN}

Berdasarkan hasil penelitian analisis bivariat menunjukkan $p$-value $=0,000$, karena $p$-value $<0,05$ maka hipotesis kerja diterima yaitu ada hubungan antara pengetahuan keluarga tentaang diet diabetes mellitus dengan kadar gula darah pasien di wilayah kerja Puskesmas Pringsewu tahun 2019. Hal ini sesuai dengan teori yang menyatakan bahwa setiap pasien DM perlu mendapatkan informasi tentang DM yang mencakup: pengetahuan dasar tentang DM, pemantauan mandiri, penyebab tingginya kadar glukosa darah, obat hipoglikemia oral, diit diabetes mellitus, pemeliharaan kaki, kegiatan jasmani, pengaturan pada saat sakit, dan komplikasi. Penyampaian informasi tersebut harus secara bertahap. Harus dihindari informasi yang terlalu sedikit atau terlalu banyak dalam waktu yang singkat. Dalam menyampaikan informasi, faktor yang perlu diperhatikan adalah kondisi pasien DM, baik kondisi fisik dalam hal ini beratnya penyakit maupun kondisi psikologis ${ }^{8}$.

Tujuan pendidikan kesehatan bagi pasien DM dan keluarga adalah meningkatkan pengetahuan karena pengetahuan merupakan titik tolak perubahan sikap dan gaya hidup. Pada akhirnya yang menjadi tujuan pendidikan adalah perubahan perilaku pasien DM dan meningkatnya kepatuhan yang selanjutnya meningkatkan kualitas hidup. Perlu kerjasama yang baik antara petugas kesehatan, pasien DM dan keluarganya agar pengobatan DM dapat berhasil ${ }^{2}$. Beberapa teori perubahan perilaku kesehatan yang menunjukkan bahwa keluarga adalah pengaruh utama, baik pada status kesehatan maupun pada perilaku kesehatan anggota keluarga ${ }^{9}$.

Keluarga dapat memberikan dukungan emosional dan psikologis membantu mempromosikan perilaku yang sehat. Keluarga dapat membantu menyediakan diit
DM sesuai aturan. Dengan diit DM. yang baik gula darah akan stabil sedangkan diit DM yang tidak baik akan memperburuk kondidi gula darah pasien. Keluarga juga dapat membantu pasien dalam setiap kontrol rutin di pelayanan kesehatan. Pengetahuan lain yang harus ditingkatkan baik pasien maupun keluarga adalah seperti pengendalian penyebabnya, yang meliputi pengendalian kenaikan berat badan bisa mengarah kepada timbulnya obesitas, pengendalian timbulnya komplikasi penyakit lain, serta perencanaan diit dan olah raga yang sesuai dengan pedoman untuk penderita $\mathrm{DM}^{10}$.

Hal ini juga sesuai juga dengan pendapat ${ }^{11}$ yang menyatakan bahwa salah satu faktor yang menentukan perilaku kesehatan seseorang adalah tingkat pengetahuan. Menurut pendapat ${ }^{12}$ dengan meningkatnya pengetahuan pasien DM dapat melakukan penatalaksanaan penyakitnya sehingga kondisi kesehatan pasien menjadi lebih baik. Dimana monitor glukosa darah merupakan hal utama dalam pengelolaan penyakit DM. Pemantauan kadar glukosa darah merupakan bagian yang tak terpisahkan dari pengelolaan DM, karena dengan pengendalian kadar glukosa darah yang baik dapat menurunkan risiko terjadinya komplikasi kronis diabetes.

Penelitian yang dilakukan muhibuddin menunjukkan ada pengaruh yang signifikan antara pengetahuan dan sikap keluarga terhadap terkendalinya kadar gula darah pada pasien DM, dengan hasil $\mathrm{p}$ value $<0,05$. Selain itu didapatkan juga bahwa sikap keluarga memberi pengaruh terhadap terkendalinya kadar gula darah pasien sebesar $37 \%{ }^{13}$. Hasil penelitian ini pula didukung oleh penelitian Handayani yang menyatakan bahwa ada hubungan tingkat pengetahuan dan dukungan keluarga terhadap kepatuhan diit pasien DM tipe II. Penelitian ini juga menunjukkan bahwa semakin baik tingkat pengetahuan terhadap diit penyakit DM 
maka subyek penelitian menjadi semakin patuh dalam menjalankan diitnya ${ }^{14}$.

Dari hasil penelitian ini, peneliti berpendapat bahwa intervensi pendidikan kesehatan selain diberikan kepada penderita juga diberikan kepada keluarga, karena keluarga berperan dalam perawatan penderita Diabetes Mellitus seperti 5 fungsi keluarga. Salah satu fungsi keluarga tersebut yatu fungsi perawatan atau pemeliharaan kesehatan (The Health Care Function) adalah untuk mempertahankan keadaan kesehatan anggota keluarga agar tetap memiliki produktivitas yang tinggi. Fungsi ini dikembangkan menjadi tugas keluarga di bidang kesehatan. Peran keluarga dalam merawat penderita Diabetes Mellitus sangat diperlukan terutama dalam menjaga diit diabetes mellitus sehingga kadar gula darah pasien menjadi terkontrol.

\section{KESIMPULAN}

Hasil penelitian ini mendapatkan nilai $\mathrm{p}$ value < 0,05 yaitu 0,000 yang berarti bahwa Ada hubungan antara pengetahuan keluarga tentang diit Diabetes Mellitus dengan kadar gula darah pasien di wilayah kerja Puskesmas Pringsewu tahun 2019.

\section{DAFTAR PUSTAKA}

1. Tarwoto, et.al. 2011. Keperawatan Medikal Bedah Gangguan Sistem Endokrin.CV. Trans Info Media, Jakarta.

2. Soewondo. 2008. Pemantauan Pengendalian Diabetes Melitus. Balai buku, Jakarta

3. Hasdianah. 2012. Mengenal Diabetes Melitus Pada Orang Dewasa dan Anak-Anak Dengan solusi Herbal. Nuha Medika, Yogyakarta

4. Riskedas, 2018. Riset Kesehatan Dasar. Kementrian Kesehatan RI, 87-90.
5. Dinas Kesehatan Propinsi Lampung. 2018. Profil Kesehatan Propinsi Lampung.

6. Waspadji. 2008. Diabetes Melitus, Penyakit Kronik dan Pencegahannya. .Pelaksanaan Diabetes Terpadu. FKUI, Jakarta.

7. Waspadji. 2008. Diabetes Melitus, Penyakit Kronik dan Pencegahannya. .Pelaksanaan Diabetes Terpadu. FKUI, Jakarta.

8. Wallace, et all. 2014. Family-Based Diabetes Intervention for Hispanic Aduls and Treir Family Members.Diabetes Educ.JanFeb;40(1):48-59.

9. Friedman. 2010. Buku Ajar Keperawatan Keluarga. EGC, Jakarta.

10. Wallace, et all. 2014. Family-Based Diabetes Intervention for Hispanic Aduls and Treir Family Members.Diabetes Educ.JanFeb;40(1):48-59.

11. Notoatmodjo. 2012. Promosi Kesehatan dan Perilaku Kesehatan. PT Rineka Citra, Jakarta.

12. Soewondo. 2008. Pemantauan Pengendalian Diabetes Melitus. Balai buku, Jakarta.

13. Muhibuddin, et all. 2016. Hubungan Pengetahuan dan Sikap Keluarga dengan Terkendalinya Kadar Gula Darah Pada Pasien Diabetes Mellitus Tipe 2. JSK.Vol.2.No.1.

14. Handayani, et all. 2017. Hubungan Tingkat Pengetahuan dan Dukungan Keluarga Terhadap Kepatuhan Diet Pasien Diabetes Mellitus di Klinikn Bhakti Husada Purwakarta. Jurnal of Holistic and Health Sciences.Vol.1.No.1. 